\title{
Corrosive Inhibitive Study of Stainless Steel in Hydrochloric Acid Using Eco-Friendly Sesmum Indicum Oil
}

\author{
ANURAG SHARMA ${ }^{1 *}$, PREETI CHOUDHARY ${ }^{2}$, \\ ANIL KUMAR VARSHNEY ${ }^{2}$ and SARITA VARSHNEY ${ }^{2}$ \\ 'Swami Keshvanand Institute of Technology, Management \& Gramothan, Jaipur, Rajasthan, India. \\ ${ }^{2}$ Department of Chemistry, University of Rajasthan, Jaipur, Rajasthan, India. \\ ${ }^{*}$ Corresponding author E-mail: anuragsharma20oct@yahoo.co.in \\ http://dx.doi.org/10.13005/ojc/330343 \\ (Received: April 01, 2017; Accepted: May 16, 2017)

\begin{abstract}
The inhibitive and adsorptive properties of Sesmum indicum eco-friendly oil for stainless steel corrosion in hydrochloric acid was investigated using weight loss technique as well as electrochemical technique. The result has proved that the oil is excellent inhibitor for stainless steel in hydrochloric acid. The inhibition efficiency of oil for stainless steel increased with increase the amount of oil. The mechanism of the oil on the surface of stainless steel was found to be spontaneous, exothermic and physical adsorption. The experimental data fitted well to Langmuir adsorption isotherms. Obtained results were justified from the galvanostatic polarization method.
\end{abstract}

Keywords: Langmuir adsorption, Weight loss technique, Sesmum indicum oil, Electrochemical technique.

\section{INTRODUCTION}

Stainless steel's strength, resistance to corrosion and low maintenance make it the ideal material for a wide range of applications such as pharmaceutical industry, architecture, medical, energy, heavy industry, construction, automotive, transportation, food and catering.

Corrosion is chemical or electrochemical reaction between materials, usually a metal, and its environment that produces a deterioration of the material. The annual loss due to corrosion has been estimated for any country at about 4 percent of gross domestic product.

In stainless steel there are some amounts of chromium which can be able to forms a passive film, this passive film can protect metal from corrosive medium. Corrosion inhibitors can protect passive film from corrosive medium. Due to chloride ions pitting corrosion is occur in stainless steel which 
is a great problem, face by engineers. Generally the loss of equipment is done by pitting corrosion. Many organic compounds have been studied as corrosion inhibitor for different metals ${ }^{1-8}$. Larger amount of organic compounds have been use as inhibitor but they are poisonous and expensive, some ecofriendly, less costly and green inhibitors are substitute of organic inhibitors ${ }^{9-12}$. Due to above reason in the present study eco-friendly Sesmum indicum oil has been tested for corrosion inhibitive property for the stainless steel metal in $0.5 \mathrm{~N}$ hydrochloric acid.

\section{EXPERIMENTAL}

\section{Weight loss method}

Material preparation

Stainless steel coupons with major amount of iron (80\%) and lesser amount of chromium (14\%) with rectangular size $3 \times 2 \times 0.2 \mathrm{~cm}$. were used for mass loss method. These coupons washed with acetone and double-distilled water, dried in electrical oven and then stored in dessicator. The same metal was used for polarization studies in which metal was coated with araldite and only $1.0 \mathrm{~cm}^{2}$ area was opened for electrochemical study.

\section{Solutions}

$0.5 \mathrm{~N} \mathrm{HCl}$ was prepared in $A R$ grade chemical for mass loss and polarization study. The amount of Sesmum indicum in corrosive medium was of $1.0 \mathrm{~g}$ to $6.0 \mathrm{~g}$ in $1000 \mathrm{ml}$ for mass loss method and $1.0 \mathrm{~g}$ to $5.0 \mathrm{~g}$ in $1000 \mathrm{ml}$ corrosive medium for polarization studies.

\section{CR (Corrosion rate) computation}

The data of mass loss was determined using following method reported earlier ${ }^{13}$. Experiment was done in repeatedly in test solution. All of first the coupons of stainless steel weighted and after this all are dipped in test solutions, which containing $0.5 \mathrm{~N}$ $\mathrm{HCl}$ with absence and presence of oil by the hooks, which are made by glass. The stainless steel coupons got back from the tested solution. The coupons rubbed for clean and after this dried in electrical oven, again weight and loss of weight was evaluated. This method have been repeated for different immersion

Table 1: \%IE, CR and surface covered by metal evaluated by mass loss experiment with stainless steel in hydrochloric acid (Experiment period : 1h)

\begin{tabular}{lcccc}
\hline $\begin{array}{l}\text { Concentration } \\
\text { of oil(gram/liter) }\end{array}$ & $\begin{array}{c}\text { Loss of metal } \\
\text { (gram) }\end{array}$ & $\begin{array}{c}\text { Efficiency of } \\
\text { inhibitor (\%) }\end{array}$ & $\begin{array}{c}\text { CR } \\
\text { (mmpy) }\end{array}$ & $\begin{array}{c}\text { Surface covered } \\
\text { by inhibitor }(\theta)\end{array}$ \\
\hline 0.00 & 0.0115 & - & 9.093 & - \\
1.00 & 0.0028 & 75.65 & 2.214 & 0.7565 \\
2.00 & 0.0025 & 78.28 & 1.97 & 0.7828 \\
3.00 & 0.0021 & 81.73 & 1.66 & 0.8173 \\
4.00 & 0.0018 & 84.34 & 1.56 & 0.8434 \\
5.00 & 0.0015 & 86.95 & 1.18 & 0.8695 \\
6.00 & 0.0012 & 89.56 & 0.94 & 0.8956 \\
\hline
\end{tabular}

Table 2: \%IE, CR and surface covered by metal evaluated by mass loss experiment with stainless steel in hydrochloric acid (Experiment period: $3 \mathrm{~h}$ )

\begin{tabular}{lcccc}
\hline $\begin{array}{l}\text { Concentration of } \\
\text { oil(gram/liter) }\end{array}$ & $\begin{array}{c}\text { Loss of metal } \\
\text { (gram) }\end{array}$ & $\begin{array}{c}\text { Efficiency of } \\
\text { inhibitor (\%) }\end{array}$ & $\begin{array}{c}\text { CR } \\
\text { (mmpy) }\end{array}$ & $\begin{array}{c}\text { Surface covered } \\
\text { by inhibitor }(\theta)\end{array}$ \\
\hline 0.00 & 0.0150 & - & 3.95 & - \\
1.00 & 0.0051 & 66 & 1.34 & 0.66 \\
2.00 & 0.0045 & 70 & 1.18 & 0.70 \\
3.00 & 0.0040 & 73 & 1.05 & 0.73 \\
4.00 & 0.0036 & 76 & 0.94 & 0.76 \\
5.00 & 0.0030 & 80 & 0.79 & 0.80 \\
6.00 & 0.0024 & 84 & 0.63 & 0.84 \\
\hline
\end{tabular}


times 1hour, 3 hours, 6 hours, 15 hours and 24 hours at room temperature (298K).

The corrosion rate (CR) was evaluated by following formula:

$\mathrm{CR}(\mathrm{mmpy})=\frac{87.6 \mathrm{~W}}{\mathrm{dAt}}$

In above formula $\mathrm{d}=$ density of the coupon $\left(\mathrm{gcm}^{-3}\right), \mathrm{W}=$ mass loss of metal $(\mathrm{mg}), \mathrm{A}=$ area of the coupon (square inch) and $t=$ time (hrs).

The \%IE with eco-friendly Sesmum indicum oil calculated using the following formula:

$\% \mathrm{IE}=1-\frac{\mathrm{Wi}}{\mathrm{W}_{0}} \times 100$

Where $\mathrm{W}_{\mathrm{o}}=$ Mass loss of the stainless steel specimens in the absence of Sesmum indicum oil and $\mathrm{W}_{\mathrm{i}}=$ Mass loss of the stainless steel specimens in presence of Sesmum indicum oil.
The $\theta$ which is surface coverage was evaluated by following formula (3)

Surface coverage $(\theta)=1-\frac{\mathrm{W} i}{\mathrm{Wo}_{0}}$

\section{Electrochemical procedure}

The galvanostatic polarization was done with three-electrode polarization cell. Polarization method have a working electrode which was prepared by stainless steel metal with $1 \mathrm{~cm}^{2}$ open area, auxiliary electrode which was prepared by platinum, reference electrode which was prepared by saturated calomel electrode.

\section{Experimental results}

The inhibitor efficiency (IE \%) of Sesmum indicum oil, degree of surface coverage $(\theta)$ by Sesmum indicum oil and CR (corrosion rate) with variable amount of the inhibitor in $0.5 \mathrm{~N} \mathrm{HCl}$ for 1 hour, 3hours, 6hours, 15hours and 24hours immersion periods and different kinetic and thermodynamic parameters were evaluated by weight loss method.

Table $3 \%$ IE, CR and surface covered by metal evaluated by mass loss experiment with stainless steel in hydrochloric acid (Experiment period: 6h)

\begin{tabular}{lcccc}
\hline $\begin{array}{l}\text { Concentration of } \\
\text { oil(gram/liter) }\end{array}$ & $\begin{array}{c}\text { Loss of metal } \\
\text { (gram) }\end{array}$ & $\begin{array}{c}\text { Efficiency of } \\
\text { inhibitor (\%) }\end{array}$ & CR (mmpy) & $\begin{array}{c}\text { Surface covered by } \\
\text { inhibitor }(\theta)\end{array}$ \\
\hline 0.00 & 0.0180 & - & 2.37 & - \\
1.00 & 0.0071 & 60.55 & 0.93 & 0.6055 \\
2.00 & 0.0068 & 62.22 & 0.89 & 0.6222 \\
3.00 & 0.0064 & 64.44 & 0.84 & 0.6444 \\
4.00 & 0.0055 & 69.44 & 0.72 & 0.6944 \\
5.00 & 0.0047 & 73.88 & 0.61 & 0.7388 \\
6.00 & 0.0038 & 78.88 & 0.50 & 0.7888 \\
\hline
\end{tabular}

Table 4: \%IE, CR and surface covered by metal evaluated by mass loss experiment with stainless steel in hydrochloric acid (Experiment period: 15h)

\begin{tabular}{lcccc}
\hline $\begin{array}{l}\text { Concentration of } \\
\text { oil(gram/liter) }\end{array}$ & $\begin{array}{c}\text { Loss of metal } \\
\text { (gram) }\end{array}$ & $\begin{array}{c}\text { Efficiency of } \\
\text { inhibitor (\%) }\end{array}$ & CR (mmpy) & $\begin{array}{c}\text { Surface covered } \\
\text { by inhibitor }(\theta)\end{array}$ \\
\hline 0.00 & 0.0225 & - & 1.18 & - \\
1.00 & 0.0095 & 57.77 & 0.50 & 57.77 \\
2.00 & 0.0086 & 61.77 & 0.45 & 61.77 \\
3.00 & 0.0081 & 64.00 & 0.42 & 64.00 \\
4.00 & 0.0073 & 67.55 & 0.38 & 67.55 \\
5.00 & 0.0067 & 70.22 & 0.35 & 70.22 \\
6.00 & 0.0061 & 72.88 & 0.32 & 72.88 \\
\hline
\end{tabular}




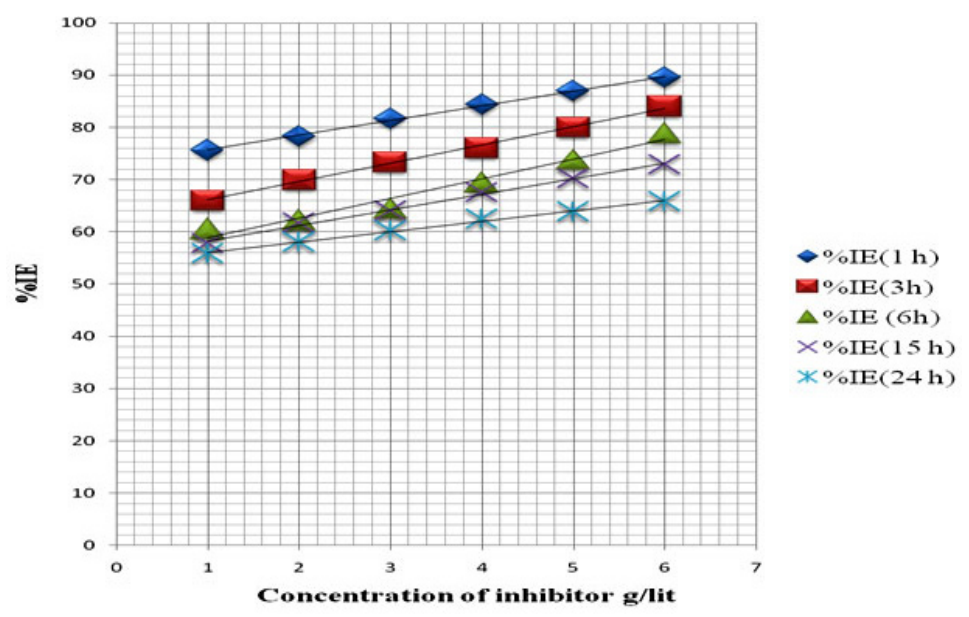

Fig. 1: Increasing of \%IE with concentration of Sesmum indicum oil for stainless steel (immersion time periods: 1 hour, 3 hour, 6 hour, 15 hour and 24 hour) in $0.5 \mathrm{~N} \mathrm{HCl}$.

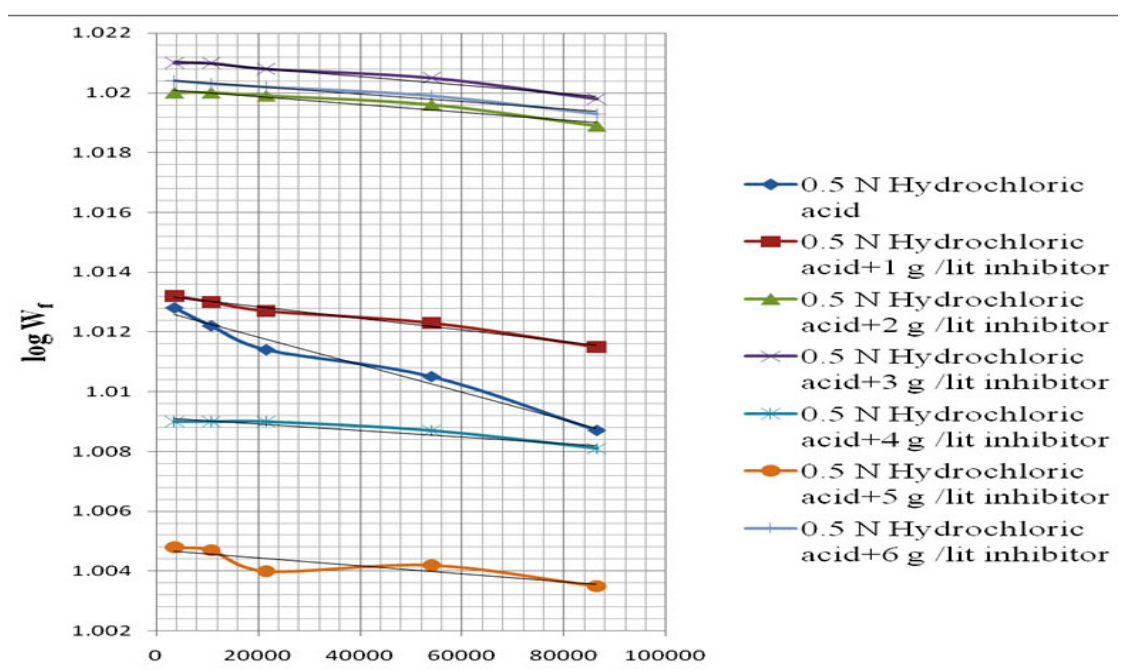

Time in sec.

Fig.2: Chemical kinetic of stainless steel in hydrochloric acid absence and presence of oil.

Table 5: \%IE, CR and surface covered by metal evaluated by mass loss experiment with stainless steel in hydrochloric acid (Experiment period: $24 \mathrm{~h}$ )

\begin{tabular}{lcccc}
\hline $\begin{array}{l}\text { Concentration of } \\
\text { oil(gram/liter) }\end{array}$ & $\begin{array}{c}\text { Loss of metal } \\
\text { (gram) }\end{array}$ & $\begin{array}{c}\text { Efficiency of } \\
\text { inhibitor (\%) }\end{array}$ & CR (mmpy) & $\begin{array}{c}\text { Surface covered by } \\
\text { inhibitor ( } \theta \text { ) }\end{array}$ \\
\hline 0.00 & 0.0410 & - & 1.35 & \\
1.00 & 0.0181 & 55.85 & 0.59 & 0.5585 \\
2.00 & 0.0172 & 58.04 & 0.56 & 0.5804 \\
3.00 & 0.0163 & 60.24 & 0.53 & 0.6024 \\
4.00 & 0.0154 & 62.43 & 0.50 & 0.6243 \\
5.00 & 0.0148 & 63.90 & 0.48 & 0.6390 \\
6.00 & 0.0140 & 65.85 & 0.46 & 0.6585 \\
\hline
\end{tabular}


Electrochemical parameters were evaluated by galvanostatic polarization method. Different parameters evaluated from mass loss procedure are presented in tables 1 to 5 . In $0.5 \mathrm{~N} \mathrm{HCl}$ at $1 \mathrm{~g} / \mathrm{lit}$ of Sesmum indicum oil, there is $75.65 \%$ inhibition observed for immersion time 1 hour. On increasing the concentration 1 to $6 \mathrm{~g} / \mathrm{lit}$, the inhibition increases up to $89.56 \%$. When the duration of immersion varied from 1 hour to 24 hours inhibitor efficiency decreases.

Weight loss measurements indicate that the dissolution rate decreases to significant extent due to the presence of oil especially at high concentrations. The inhibition efficiency is maximum on immersion time 1 hour at $6 \mathrm{~g} / \mathrm{lit}$ Sesmum indicum. The maximum inhibition efficiency for immersion time 24 hours at $6 \mathrm{~g} / \mathrm{lit}$ Sesmum indicum is $65.85 \%$. The graph which is present in figure 1 shows that \%IE is varies with the amount of the Sesmum indicum oil with variable experimental times like 1 hour, 3 hours, 6 hours, 15 hours and 24 hours.

Table 6: Kinetic parameter study of protection and destruction of stainless steel in acidic medium with and without of oil

\begin{tabular}{lcc}
\hline $\begin{array}{l}\text { Sesmum indicum oil } \\
\text { Amount (gram/liter) }\end{array}$ & $\mathbf{k}\left(\mathbf{s}^{-1}\right)$ & $\mathbf{t}_{1 / 2}(\mathbf{s})$ \\
\hline 0.00 & $1.15 \times 10^{-7}$ & $5.02 \times 10^{6}$ \\
1.00 & $4.6 \times 10^{-8}$ & $1.50 \times 10^{7}$ \\
2.00 & $2.3 \times 10^{-8}$ & $3.0 \times 10^{7}$ \\
3.00 & $2.3 \times 10^{-8}$ & $3.0 \times 10^{7}$ \\
4.00 & $2.3 \times 10^{-8}$ & $3.0 \times 10^{7}$ \\
5.00 & $2.3 \times 10^{-8}$ & $3.0 \times 10^{7}$ \\
6.00 & $2.0 \times 10^{-8}$ & $3.4 \times 10^{7}$ \\
\hline
\end{tabular}

Table 7: Adsorption parameters of Sesmum indicum oil on the stainless steel surface in hydrochloric acid for different experimental periods

\begin{tabular}{lllll}
\hline $\begin{array}{l}\text { Experimental } \\
\text { Time periods }\end{array}$ & $\mathbf{K}_{\text {ad }}$ & Slope & $-\Delta \mathbf{G}_{\text {ads }}$ & $\mathbf{R}^{2}$ \\
\hline 1 hour & 2.71 & 1.0 & 25.39 & 0.9979 \\
3hour & 1.77 & 1.1 & 20.02 & 0.9943 \\
6 hour & 1.27 & 1.1 & 17.17 & 0.9861 \\
15 hour & 1.63 & 1.2 & 19.22 & 0.9964 \\
24 hour & 2.10 & 1.4 & 21.91 & 0.9983 \\
\hline
\end{tabular}

Corrosion kinetics of stainless steel in hydrochloric acid with inhibitor

Figure 2 present a graph which shows log $\mathrm{W}_{\mathrm{f}}$ (weight of stainless steel at time $\mathrm{t}$ ) is change with time, the evaluated data putted in to the rate law for first order reaction. The plots are linear, which concluded that the reaction with stainless steel in test solution follows first order kinetic ${ }^{14-15}$. The rate constants measured from the figure 2 are concluded in table 6.

$$
\log \frac{W i}{\Delta W t}=-\frac{k}{2.303} t+\log W i
$$
giving below.

The half-life $\left(t_{1 / 2}\right)$ evaluated from equation $\left(t_{1 / 2}\right)=0.69 \mathrm{k}$

The half life were evaluated by above formula are shows in table 6 which clearly shows that rate constant inversely proportional of half life which conclude the protection of metal by inhibitor.

Thermodynamic parameters of stainless steel in hydrochloric acid with inhibitor

The graph of $C / \theta$ vs $C$ presents linearity in figure 3 . This conclude that adsorption of oil molecules on stainless steel metal surface follows Langmuir isotherm. According to Langmuir adsorption isotherm degree of surface coverage $(\theta)$ of stainless steel and the concentration of the inhibitor in hydrochloric acid are related to following formula (6).

$$
\mathrm{C} / \theta=1 / \mathrm{K}_{\mathrm{ad}}+\mathrm{C}
$$

Average values for free energy of adsorption $\left(\Delta \mathrm{G}_{\mathrm{ads}}\right)$, were calculated using the following equations 7.

$\Delta \mathrm{G}_{\mathrm{ads}}=-\mathrm{RT} \ln (55.5 \mathrm{~K})$

$\mathrm{K}$ = equilibrium constant, $\mathrm{R}=$ gas constant and $T=$ temperature. It is found that the $\Delta G_{\text {ads }}$ values for the studied compound are less than $-40 \mathrm{~kJ} \mathrm{~mol}^{-1}$, indicating that the Sesmum indicum oil are physically adsorbed on stainless steel. The less and negative value of $\Delta G_{\text {ads }}$ shows the spontaneous adsorption reaction of the oil on the stainless steel ${ }^{16-18}$ 


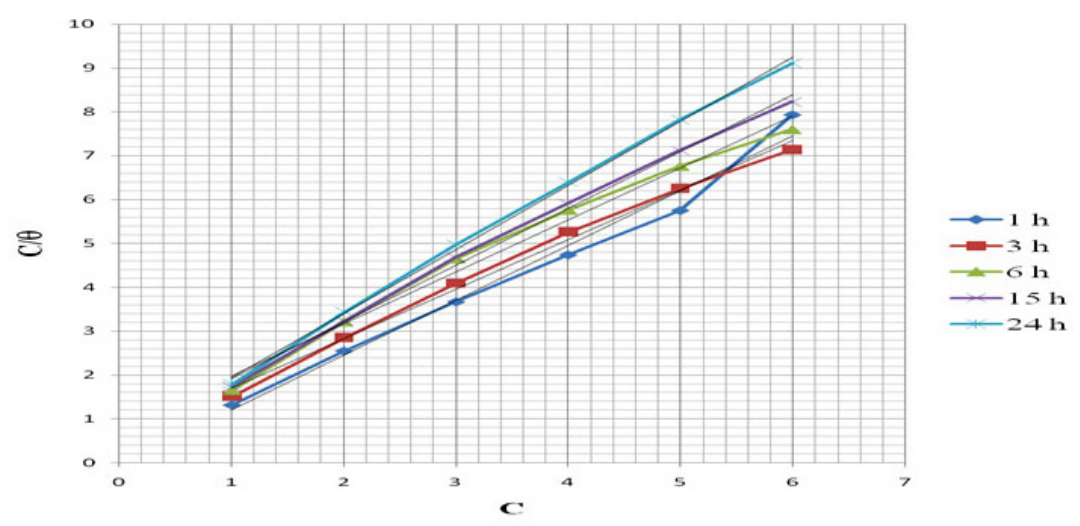

Fig. 3: Langmuir adsorption isotherm with stainless steel in hydrochloric acid with different amount of oil for different experimental time

Table 8: Electrochemical polarization parameters for stainless steel in hydrochloric acid without and with Sesmum indicum oil

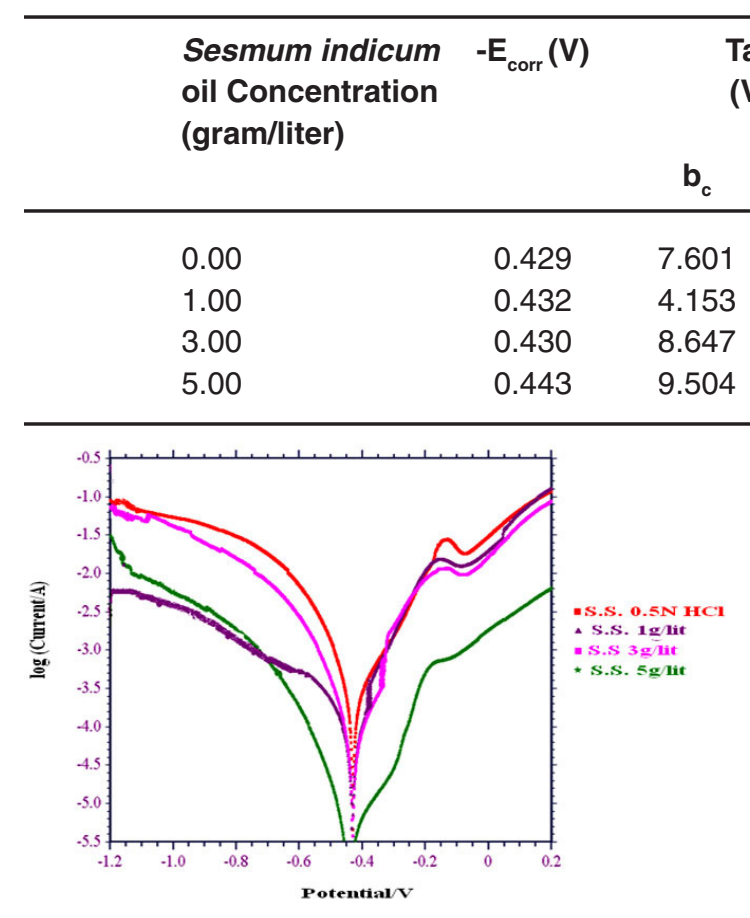

Fig. 4: Polarization curve of stainless steel in $0.5 \mathrm{~N} \mathrm{HCl}$ without and with of oil concentrations

\section{Galvanostatic polarization studies}

The polarization data of stainless steel working as a cathode and an anode in absence and presence of Sesmum indicum oil with hydrochloric acid is shown in figure 4 . The electrochemical polarization parameters concluded from figure 4 like corrosion current $\mathrm{I}_{\text {corr }}$, Tafel constant $\mathrm{b}_{\mathrm{a},} \mathrm{b}_{\mathrm{c}}$ and

\begin{tabular}{|c|c|}
\hline $\begin{array}{l}\text { Tafel slopes } \\
(\text { V.dec-1) }\end{array}$ & $I_{\text {corr }}\left(A \cdot \mathrm{cm}^{-2}\right)$ \\
\hline
\end{tabular}

$\left(\right.$ V.dec $\left.^{-1}\right)$

$\mathbf{b}_{\mathbf{a}}$

$\begin{array}{ccc}6.765 & 3.163 \times 10^{-4} & - \\ 8.542 & 1.103 \times 10^{-4} & 65.13 \\ 14.88 & 5.929 \times 10^{-5} & 81.25 \\ 6.506 & 5.207 \times 10^{-6} & 98.35\end{array}$

$\mathrm{E}_{\text {corr }}$ are tabulated in table 8.

A decrease in the corrosion current and increase in the cathodic and anodic Tafel slopes have been observed with the grater in the amount of oil. $\mathrm{E}_{\text {corr }}$ values have not significant change with the addition of inhibitor. The inhibition efficiencies determined from the values of corrosion current are found to be in comparable with those obtained from weight loss measurement. The inhibition efficiencies determined by following equation:

( Inhibitor efficiency ) IE\%=1-( $\left.I_{\text {corr }}{ }^{1} I_{\text {corr }}\right) \times 100$

In the present equation $\mathrm{I}_{\text {corr }}=$ current densities with Sesmum indicum oil in $0.5 \mathrm{~N}$ hydrochloric acid $\mathrm{I}_{\text {corr }}{ }_{\text {of }}$ current densities without of Sesmum indicum oil in hydrochloric acid. The presence of passive region in the graph as shown in figure 4 may be due to the protection layers of chromium and iron oxide formed from their respective 
metals present in stainless steel. Chloride ions which are present in hydrochloric acid destroy the protective layers which are made by oil and generate pits on the stainless steel surface. $I_{\text {critical }}$ is maximum when no inhibitor was added to $0.5 \mathrm{~N} \mathrm{HCl}$ (uninhibited solution) the values of $\mathrm{I}_{\text {critical }}$ decreases with increased concentration of inhibitor suggesting inhibitor is capable of reducing corrosion.

\section{CONCLUSIONS}

By the evaluated data from weight loss and polarization study the following conclusion can be explain:

1. The eco friendly Sesmum indicum oil was concluded as a best inhibitor for stainless steel in $0.5 \mathrm{~N}$ hydrochloric acid.

2. Inhibition efficiency directly proportional with the amount of Sesmum indicum oil content up to $6 \mathrm{~g} /$ liter to reach $89.56 \%$ in $0.5 \mathrm{~N} \mathrm{HCl}$ at room temperature.

3 Kinetics analyses of data showed linear variations, which confirm a first order kinetics in hydrochloric acid.

4. The above research concluded that adsorption of oil molecules on stainless steel metal surface follows Langmuir isotherm in hydrochloric acid medium.

5. The less and negative value of $\Delta \mathrm{G}_{\text {ads }}$ shows the spontaneous adsorption reaction of the Sesmum indicum oil on the stainless steel surface.

6. Obtained results were justified from the galvanostatic polarization method.

7. The values $\mathrm{E}_{\text {corr }}$ obtained from galvanostatic polarization method are mostly constant, by this we can conclude that Sesmum indicum oil work as mixed type in hydrochloric acid and retard both the reaction in equal amount on anodic and cathodic ends.

\section{ACKNOWLEDGEMENTS}

The authors gratefully acknowledge the Head of department, Chemistry, University of Rajasthan, Jaipur and Prof.(Dr.) S. L. Surana Director (Academic), Swami Keshvanand Institute of Technology, Management \& Gramothan, Jaipur for providing necessary facilities.

\section{REFERENCES}

1. Chadli, R., Elazouzi, M., Khelladi, I., Elhourri, A.M., Elmsellem, H., Aouniti, A., Mulengi, J. K., Hammouti, B., Port. Electrochim. Acta, 2017, 35(2), 65-80.

2. Fouda, A.S., Diab, M. A., Fathy, S., Int. J. Electrochem. Sci., 2017, 12, 347 - 362.

3. Yadav M., Gope L., Kumari N., Yadav P, ELSEVIER, Journal of Molecular Liquids, 2016, 216, 78-86.

4. Fouda, A. S., Abdallah, Y.M., Nabil, D., Int. Journal of Innovative Research in Science, Eng. and Tech., 2014, 3 (5), 12965- 12982.

5. Srivastava, K., Singh, P., Quraishi, M.A., Int. J. Innovative Research in Science, Engineering and Technology, 2016, 5 (3), 3401-3405.

6. Ezhilarasi, M. R., Prabha, B. , Santhi, T., Rasayan J. Chem., 2015, 8 (1), 71-83.

7. Vinutha, M.R., Venkatesha, T.V., Portugaliae Electrochimica Acta, 2016, 34(3), 157-184.

8. Fouda, S., Abd El-Maksoud, S., Gomaa,
S.A., Elsalakawy, A., Journal of Applicable Chemistry, 2017, 6 (1), 160-175.

9. Sharma, A., Varshney, A. K., Varshney, S., Orient. J. Chem., 2016, 32(5), 2769-2775.

10. Sharma, A., Rawat, J. Varshney, A. K., Verma, P. S., Varshney, S., J. Indian Chem. Soc., 2010, 87, 573-577.

11. Gobara, M., Baraka, A. , Zaghloul, B., Springer, 2015, 41, 9885-9901.

12. Afia, L., Benali, O., Salghi, R., Ebenso, E. E., Jodeh, S., Zougagh, M., Hammouti, B., Int. J. Electrochem. Sci., 2014, 9, 8392-8406.

13. Afolabi, A. S., Muhirwa, A. C., Abdulkareem, A. S, Muzenda E., Int. J. Electrochem. Sci., 2014, 9, 5895 - 5906.

14. Mani, N., Venkatakrishna lyer, S., Bahadur, L., Transactions of the SAEST, 2003, 38(2), 67-71.

15. Patil, D.B., Sharma, A.R., E-Journal of Chemistry, 2011, 8(S1), S358-S362. 
16. Joseph, T. N., Okafor, V. N., Journal of Minerals and Materials Characterization and Engineering, 2012, 11, 885-890.

17. Abdallaha, M., Zaafaranya, I. A., AL Jahdalya, B.A., J. Mater. Environ. Sci., 2016, 7 (4), 1107-
1118.

18. Al-Baghdadi, S.B., Noori, F.T.M., Ahmed, W.K., Al-Amiery A.A., J. of Advanced electrochem., 2016, 2(1), 67-69. 